\title{
Feature analysis on air quality in the main urban area of Nanchong City in 2015 - 2018
}

\author{
Xiong Lei ${ }^{1^{*}}$, Qing Zheng ${ }^{*}$, Yifan Qian ${ }^{1}$, Jian $\mathrm{Hu}^{1}$, Danyu $\mathrm{Li}^{1}$, Ping Zhang ${ }^{2}$, Xu Yuan ${ }^{2}$, \\ Qiumei Quan ${ }^{2+}$, Yunxiang $\mathrm{Li}^{2+}$ \\ ${ }^{1}$ Sichuan Nanchong Ecological Environment Monitoring Center, Nanchong, Sichuan, 637000, China \\ ${ }^{2}$ College of Environmental Science and Engineering, China West Normal University, Nanchong, Sichuan, 637002, China \\ "These authors contributed equally to this work.
}

\begin{abstract}
This study evaluates the air quality in Nanchong City in 2015-2018 based on automatic monitoring data and meteorological data in the main urban area. Results show that overall air quality in the main urban area of Nanchong was standard and improved from 2015 to 2018 . $\mathrm{SO}_{2}$, $\mathrm{NO}_{2}$, and $\mathrm{CO}$ had slight influences on air quality in the study area, whereas excessive annual average $\mathrm{PM}_{2.5}$ and increasing $\mathrm{O}_{3}$ concentration challenged the air quality. The monthly average mass concentrations of particulate matters $\left(\mathrm{PM}_{2.5}\right.$ and $\left.\mathrm{PM}_{10}\right)$, $\mathrm{NO}_{2}$, and $\mathrm{CO}$ generally presented a "U-shaped" distribution pattern while $\mathrm{O}_{3}$ showed the opposite. The diurnal variation of $\mathrm{PM}, \mathrm{NO}_{2}$, and $\mathrm{CO}$ has two peaks related to the morning and evening rush hours. Vehicle exhaust is the main source of local pollution. Over-standard $\mathrm{PM}_{2.5}$ can significantly inhibit $\mathrm{O}_{3}$ production while $\mathrm{O}_{3}$ can easily promote the secondary generation of $\mathrm{PM}_{2.5}$ due to its strong oxidization. $\mathrm{PM}_{2.5}$ emission should be controlled strictly in winter, while in summer, the sources of $\mathrm{O}_{3}$ should be controlled vigorously. Air pollution is comprehensive and complicated and is influenced by various factors, mainly meteorological and human factors. Measures such as artificial rainfall should be included at the appropriate time to cope with adverse meteorological conditions when heavy pollution occurs in winter.
\end{abstract}

Keywords: Air quality, Meteorological factor, Nanchong, $\mathrm{O}_{3}, \mathrm{PM}_{2.5}$

\section{Introduction}

Air pollution in China has intensified along with the progresses in industrialization and urbanization [1]. In the last 30 years, the main air pollutants in China have undergone several stages, from total suspended particulates, inhalable particles $\left(\mathrm{PM}_{10}\right)$, and sulfur dioxide $\left(\mathrm{SO}_{2}\right)$ to fine particulate matters $\left(\mathrm{PM}_{2.5}\right)$ and ozone $\left(\mathrm{O}_{3}\right)$, because of increased production capacity, energy restructuring, and a sharp increase in car ownership [2-4]. Pollution types evolved from cumulative over-standard single pollutants into composite pollution caused by the coexistence of several pollutants. At present, air pollution in most Chinese cities is identified as composite pollution [5-7], and transregional large-scale environmental problems have formed [8, 9]. Anthropogenic source is the primary one between two major sources of air pollutants [9]. Air pollution in most cities in China is the same as in Japan, Korea, and many European and
American countries [10, 11]. It is mainly influenced by production and the living activities of human beings, such as combustion of fossil fuel, combustion of biomass, industrial production and emission, and vehicle exhaust [12]. There are complicated conversion relations among pollutants that have entered the atmospheric environment and between pollutants and original air components [5]. For example, $\mathrm{SO}_{2}$ and $\mathrm{NO}_{2}$ can generate secondary particulates through homogenous and heterogeneous reactions [13], which play an important role in regional air quality and global climate changes [14]. Ozone precursors such as $\mathrm{NO}_{\mathrm{x}}$ and volatile organic compounds (VOCs) can produce near-surface $\mathrm{O}_{3}$ through photochemical reactions [15-17]. In addition, ozone is closely related to the formation of PAHs, and PAHs are seriously harmful to human body $[18,19]$. Pollutants that enter the air not only cause serious damage to the environment and the physical health of humans but may also jeopardize sustainable economic and social
This is an Open Access article distributed under the terms of the Creative Commons Attribution Non-Commercial License (http://creativecommons.org/licenses/by-nc/3.0/) which permits unrestricted non-commercial use, distribution, and reproduction in any medium, provided the original work is properly cited.

Copyright (C) 2022 Korean Society of Environmental Engineers
Received December 31, 2020 Accepted April 26, 2021

${ }^{\dagger}$ Corresponding author

E-mail: 289428117@qq.com; yx_li@cwnu.edu.cn

Tel: +86-15328858892; +86-13990732181

ORCID: 0000-0002-3057-9928 (Q.Q); 0000-0003-1751-2742 (Y.L) 
development [20-22]. A study [23] has pointed out the existence of an inverted U-shaped curve relation between economic development and pollution. In other words, air quality declines with the increase in per capita income.

Given the advances in air quality monitoring methods and the increasing efforts in air pollution study and control, air quality problems in China have generally improved significantly. Most existing research on air quality emphasizes heavily polluted big cities (e.g., Beijing-Tianjin-Hebei, Yangtze River Delta, Pearl River Delta, and Sichuan Basin) [24-29] or economically developed cities. However, there are relatively fewer studies concerning air quality in small and middle cities. China also has an extensive territory with different landforms and levels of economic development modes. Hence, measures and methods to control air pollution vary for different regions. Air pollution is generally related to climate [30]. Many studies have demonstrated that meteorological factors, such as air temperature, rainfall, and wind speed, are important influencing factors of air pollutant concentrations [13, 31, 32]. In particular, migration, transformation, dilution, and diffusion of pollutants in air are mainly determined by meteorological factors when the pollutant source is relatively stable [17, 33]. Temporal and spatial variations of air pollutants are closely related to emission source, geographic features, and climatic factors [13].

Nanchong City is located in the northeast region of Sichuan Basin. Its main urban area is at the bottom and low-lying. As conditions for the diffusion of pollutants in the city are poor, pollutants accumulate easily [34]. Having suffered great damages due to acid rain, Nanchong City implemented the coal-to-gas project in its main urban area in 2000 [35], and it has had no acid rains since 2015 [36]. Nevertheless, $\mathrm{PM}_{2.5}$ and $\mathrm{O}_{3}$ pollutions are still prominent, the same as in other Chinese cities [5, 37]. A great agricultural city, Nanchong is characteristic of cities with underdeveloped industries and a big population (the population in the main urban area reached 1.37 million in the end of 2018). The activities of residents (e.g., production and commuting) and the pollutants produced by biomass combustion in suburbs considerably influence the air quality in urban areas [38]. Although some studies on air pollution in Nanchong City (mainly short-term air quality analyses) have been reported, no long-term and systematic analysis of air quality in the main urban area of the city has been carried out. In the present study, the variation trend of air quality in the main urban area of Nanchong City in recent years was analyzed systematically using automatic monitoring data in 2015-2018. In addition, monthly and diurnal variations of air pollutants and their relations with $\mathrm{PM}_{2.5}$ and $\mathrm{O}_{3}$ were discussed by combining them with meteorological data. Causes of haze pollution and intensifying $\mathrm{O}_{3}$ pollution were likewise explored to provide references for air pollution control in Nanchong City.

\section{Study Area and Data Source}

\subsection{Study Area}

Nanchong City $\left(30^{\circ} 35^{\prime}-31^{\circ} 51^{\prime} \mathrm{N}, 105^{\circ} 27^{\prime}-106^{\circ} 58^{\prime}\right.$ E, 256-889 masl) is located in the northeast of Sichuan Basin and the midstream of Jialing River. It is the city with the second biggest population in Sichuan Province. It belongs to the mid-subtropical mild monsoon climate zone, which has cloudy and misty weather accompanied by low wind speed and quiet winds in a year, especially in winter [17]. The main urban area of Nanchong City is in the south, which includes the districts of Shunqing, Gaoping, and Jialing. It is located on the valley terrace and has low-lying terrain, with an elevation of only about $300 \mathrm{~m}$. It is high in the northwest and low in the southeast. The study area is shown in Fig. 1.

\subsection{Data Source}

Air quality data in this study were collected from automatic monitoring data in the Environmental Monitoring Center of Nanchong City from January 1, 2015 to December 31, 2018, including standard air pollutants $\left(\mathrm{PM}_{2.5}, \mathrm{PM}_{10}, \mathrm{SO}_{2}, \mathrm{CO}, \mathrm{NO}_{2}\right.$, and $\left.\mathrm{O}_{3}\right)$ and air quality index (AQI). Meteorological data were collected from the website (https://rp5.ru/), including daily data of temperature (T), air pressure (AP), relative humidity (RH), wind speed (WS), precipitation (P),

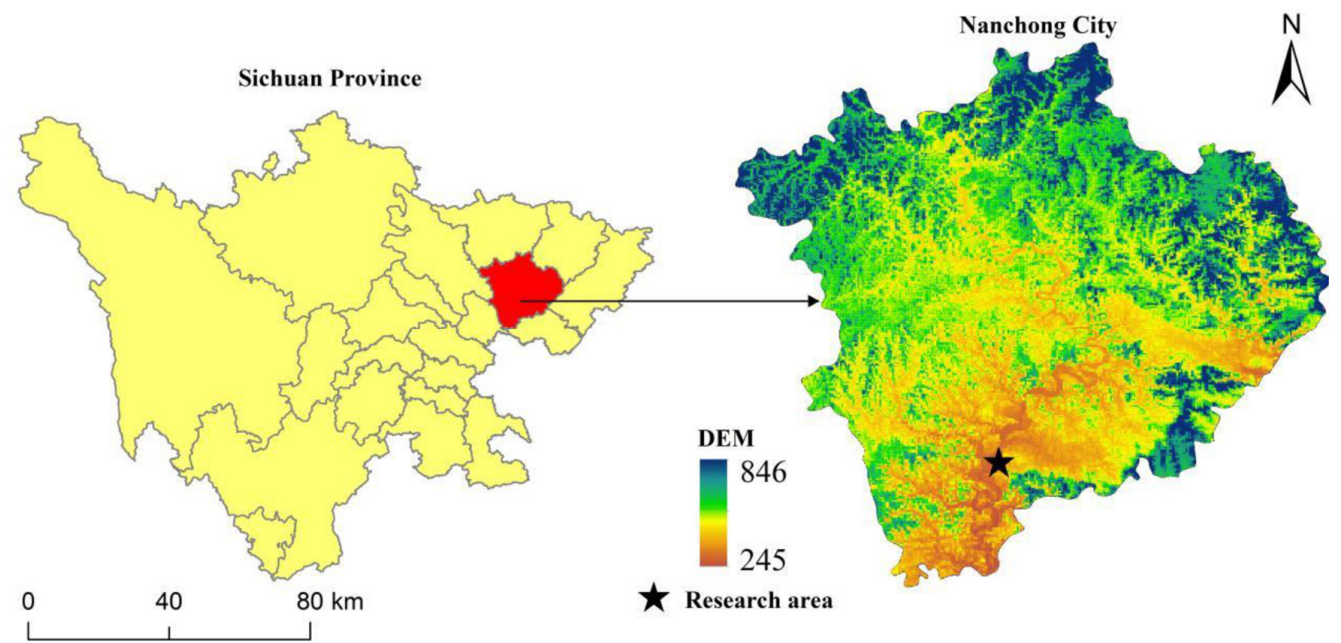

Fig. 1. Map of main urban area of Nanchong City. 
and horizontal visibility (HV). According to the meteorological division method of China, one year is divided into spring (March-May), summer (June-August), autumn (September-November), and winter (December-February the next year).

AQI is calculated as follows:

$$
\mathrm{AQI}=\max \left\{\mathrm{IAQI}_{1}, \mathrm{IAQI}_{2}, \mathrm{IAQI}_{3}, \ldots, \mathrm{IAQI}_{\mathrm{n}}\right\}
$$

where IAQI is the individual air quality index, and $\mathrm{n}$ is the pollutant project.

AQI is a dimensionless index that provides a quantitative description of air quality. The higher the numerical value of AQI, the higher the degree of pollution [17]. Air quality level is divided into six levels: I (0-50), II (51-100), III (101-150), IV (151-200), V (201-300), and VI (> 300). These six levels correspond respectively to Excellent, Good, Mild pollution, Moderate pollution, Heavy pollution, and Serious pollution. Daily AQI reaching the Excellent or Good level is viewed as meeting the standard.

\subsection{Research Method}

\subsubsection{Effects of $\mathrm{PM}_{2.5}$ on $\mathrm{O}_{3}$}

According to the grading standards of $\mathrm{PM}_{2.5}$ concentration in China [39], $\mathrm{PM}_{2.5}$ concentration is divided into three levels: $<35 \mu \mathrm{g} / \mathrm{m}^{3}$, 35-75 $\mu \mathrm{g} / \mathrm{m}^{3}$, and $>75 \mu \mathrm{g} / \mathrm{m}^{3}$. These three levels represent different air quality grades: Excellent, Good, and Polluted. The $\mathrm{O}_{3}$ concentration at the current hour minus the $\mathrm{O}_{3}$ concentration at the previous hour is the hourly variation rate of $\mathrm{O}_{3}$. Data of $\mathrm{O}_{3}$ were grouped according to $\mathrm{PM}_{2.5}$ concentration at the same time to further investigate the hourly variation intensity of $\mathrm{O}_{3}$ when $\mathrm{PM}_{2.5}$ concentration varies.

\subsubsection{Effects of $\mathrm{O}_{3}$ on $\mathrm{PM}_{2.5}$}

In this study, the effects of $\mathrm{O}_{3}$ on $\mathrm{PM}_{2.5}$ were analyzed with reference to the method of Chang et al. [40] based on the percentage of secondary particulates under different $\mathrm{O}_{3}$ concentrations. According to the grading standards of $\mathrm{O}_{3}$ in China, the data of $\mathrm{O}_{3}$ were divided into four levels: $\mathrm{O}_{3}<100 \mu \mathrm{g} / \mathrm{m}^{3}, 100-160 \mu \mathrm{g} / \mathrm{m}^{3}$, $160-200 \mu \mathrm{g} / \mathrm{m}^{3}$, and $>200 \mu \mathrm{g} / \mathrm{m}^{3}$. The mass concentration of secondary particulates is calculated as follows:

$$
\left(P M_{2.5}\right)_{S, i}=\left(P M_{2.5}\right)_{T, i}-(C O)_{T, i} \times\left(P M_{2.5} / C O\right)_{L}
$$

where $i$ is the interval of $\mathrm{O}_{3}$ concentration; $\left(P M_{2.5}\right)_{T, i}$ represents the $\mathrm{PM}_{2.5}$ concentration when the interval of $\mathrm{O}_{3}$ concentration is i; $\left(P M_{2.5}\right)_{S, i}$ denotes the secondary $\mathrm{PM}_{2.5}$ concentration when the interval of $\mathrm{O}_{3}$ concentration is $i$; $(C O)_{T, i}$ refers to the $\mathrm{CO}$ concentration when the interval of $\mathrm{O}_{3}$ concentration is $i$; and $\left(\mathrm{PM}_{2.5} / C O\right)_{L}$ represents the value of $\mathrm{PM}_{2.5} / \mathrm{CO}$ when $\mathrm{O}_{3}<100 \mu \mathrm{g} / \mathrm{m}^{3}$.

\subsection{Statistical Analysis}

The statistical analysis was conducted using the SPSS 19.0 and Excel. Specifically, relationships between air pollutants and meteorological parameters were tested using the Spearman correlation. Kruskal-Wallis test was used to investigate the differences of annual pollutants concentrations from 2015 to 2018. $P<0.05$ was considered to be of statistical significance.

\section{Results and Discussion}

\subsection{Air Quality}

Fig. 2 shows the mean AQI in the main urban area of Nanchong City in 2015-2018 was 68.52 and decreased year by year. The 75th percentile of the AQI was kept lower than 100 (Ambient air quality up to standard) for three successive years (2016-2018), and only the 95th percentile in 2015 was higher than 150 (Moderate pollution). This result reflects the significant achievements of air pollution control in recent years, as manifested by the improving air quality year by year.

When the analysis of annual average concentrations of six elements of ambient air quality in Nanchong City in 2015-2018 (Table S1) is combined with the Ambient Air Quality Standard (GB3095-2012) [39], it can be concluded that PM is the major over-standard pollutant in the study area. Specifically, $\mathrm{PM}_{2.5}$ exceeded the national Grade II standard of annual average concentration $\left(35 \mu \mathrm{g} / \mathrm{m}^{3}\right)$ for four years successively [39]. However, $\mathrm{PM}_{10}$ concentration dropped dramatically after 2016 and met the national Grade II standard of annual average concentration $\left(70 \mu \mathrm{g} / \mathrm{m}^{3}\right)$ after 2017 [39]. The concentrations of other gaseous pollutants were generally low and presented no over-standard phenomenon. The annual average concentrations of $\mathrm{NO}_{2}$ and $\mathrm{O}_{3}$ increased continuously. In particular, the annual average concentration of $\mathrm{O}_{3}$ increased year by year, and the increasing amplitude reached the significant level (Kruskal-Wallis test, $p<0.01$ ). The average $\mathrm{O}_{3}$ concentration in 2018 increased 0.75 times compared to that in 2015 and reached $88.09 \mu \mathrm{g} / \mathrm{m}^{3}$. This finding is consistent with the increasingly prominent $\mathrm{O}_{3}$ pollution in other cities in China $[41,42]$.

Zhong et al. [43] pointed out that the rate of standard ambient air quality (percentage of Excellent and Good levels of ambient air quality) in the main urban area of Nanchong City in 2014 was only $66.80 \%$, which was significantly lower than that during 2009 2013. This outcome was mainly due to the new Ambient

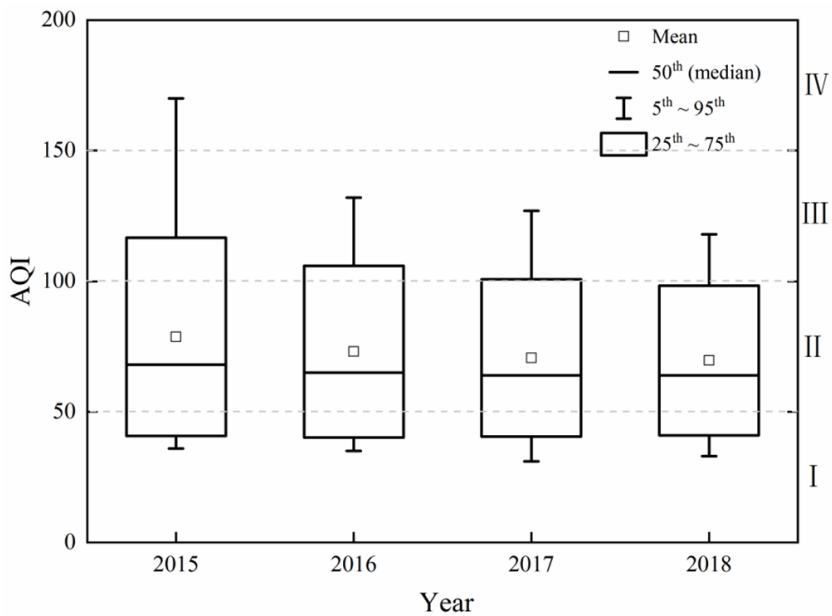

Fig. 2. Distribution of daily mean AQI in the study area during 2015-2018. (Notes: These four levels( I , I , III, IV) are corresponding to Excellent, Good, Mild pollution, Moderate pollution, respectively.) 


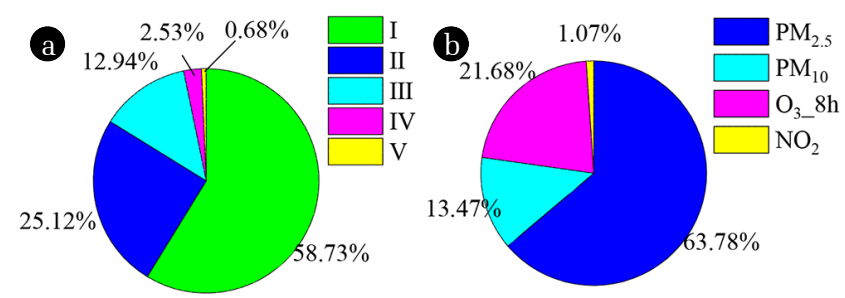

Fig. 3. (a) Number of days of air pollution at different levels in the study area during 2015-2018, (b) Percentage of main pollutants in different stages. (Notes: main pollutant is the air pollutant with the maximum IAQI when the AQI is higher than 100 at the day)

Air Quality Standard (GB3095-2012) implemented in the main urban area of Nanchong City in 2014 and the increase in the main pollutants considered to judge ambient air quality from three items $\left(\mathrm{SO}_{2}\right.$, $\mathrm{NO}_{2}$, and $\left.\mathrm{PM}_{10}\right)$ to six $\left(\mathrm{SO}_{2}, \mathrm{NO}_{2}, \mathrm{CO}, \mathrm{O}_{3}, \mathrm{PM}_{2.5}\right.$, and $\left.\mathrm{PM}_{10}\right)$ [39]. The judgment standards were increased as well, leading to a sharp rise in the number of over-standard days and a dramatic reduction in the percentage of Excellent and Good levels of ambient air quality in 2014. Similar phenomena were observed in big cities such as Beijing-Tianjin-Hebei, Yangtze River Delta, Pearl River Delta, and so on [29]. The number of days that meet the ambient air quality standard in Nanchong City has increased year by year since 2015 (Table S2). Specifically, the number of days in 2018 was 26 days higher compared to that in 2015, and the control rate reached as high as $\mathbf{8 7 . 1 2 \%}$. Fig. 3(a) illustrates that the overall percentage of Excellent and Good levels of ambient air quality reached $83.85 \%$ in four years, and Mild pollution was dominant (12.94\%) when an over-standard phenomenon of pollutants occurred. Moreover, the main air pollutant in the study area increased from the single $\mathrm{PM}_{10}$ before 2013 to the coexistence of $\mathrm{PM}_{2.5}, \mathrm{O}_{3}, \mathrm{PM}_{10}$, and $\mathrm{NO}_{2}$ after the implementation of new standards [44]. Among them, $\mathrm{PM}_{2.5}$ accounted for the highest proportion, followed successively by $\mathrm{O}_{3}, \mathrm{PM}_{10}$, and $\mathrm{NO}_{2}$ (Fig. 3(b)).

\subsection{Monthly Variation Characteristics}

Anthropogenic sources of PM in the atmospheric environment mainly include the combustion of fossil fuels, road and building dust, industrial production and emissions, and vehicle exhaust [9, 45-47, 49]. Owing to the different economic development modes and levels of cities, the contributions of various pollution sources to PM concentration in the ambient air of urban areas vary accordingly. In Nanchong City, agriculture is the major economic production, industry is not very developed, urban areas have big populations, and PM concentration is highly sensitive to biomass combustion and vehicle exhaust. The contributions of biomass combustion and vehicle exhaust to $\mathrm{PM}_{2.5}$ accounted for $17.23 \%$ and $15.53 \%$, respectively (data were collected from the analysis results of $\mathrm{PM}_{2.5}$ source in Nanchong City in 2014-2016 [34]). The $\mathrm{PM}_{2.5} / \mathrm{PM}_{10}$ reached $66.83 \%$ in 2015-2018, which presented a small difference with $\mathrm{PM}_{2.5} / \mathrm{PM}_{10}$ in other cities like Jiaozuo City [50]. Additionally, the annual average concentration of $\mathrm{NO}_{2}$ increased in the last four years, whereas the annual average concentration of $\mathrm{SO}_{2}$ declined. The mean $\mathrm{NO}_{2} / \mathrm{SO}_{2}$ was as high as 2.80, which further proved the remarkable contributions of vehicle exhaust to $\mathrm{PM}_{2.5}$.
When the pollution source is relatively stable, air pollution in cities is mainly determined by the diffusion, migration, and transformation of pollutants in air [47]. Low air pressure can lead to unstable meteorological conditions and easily cause blowing and raining while precipitation is an important mechanism in the process of wet removal $[17,51,52]$. Pollutants spread way much faster if the speed of wind goes up. Furthermore, higher temperature brings with them stronger atmospheric convective activity, which is beneficial for the migration and diffusion of pollutants [26, 51]. Fig. 4 shows that the monthly variations of $\mathrm{PM}_{2.5}, \mathrm{PM}_{10}, \mathrm{CO}$, and $\mathrm{NO}_{2}$ from January to December all presented "U-shaped" distributions (Fig. 4(a), (b)). Given the close relationship between meteorological conditions and urban air pollution [53], in the current study, the correlations of major pollutants and various meteorological factors were discussed according to the Spearman correlation (Table S3). As shown in Table S3, temperature, precipitation, wind speed, and relative humidity all show significantly negative correlations with concentrations of $\mathrm{PM}_{2.5}, \mathrm{PM}_{10}, \mathrm{CO}$, and $\mathrm{NO}_{2}$, whereas air pressure shows positive correlations. These results in combination with Fig. 4 reveal that Nanchong City has high temperature, high wind speed, rich precipitations, low air pressure, and low relative humidity in summer (Fig. 4(d)-(f)), all of which are beneficial for the migration and diffusion of pollutants. The meteorological conditions in winter are the opposite and thus disadvantageous for the migration and diffusion of pollutants [35]. Owing to the significant seasonal variations in meteorological factors, monthly average concentrations of $\mathrm{PM}_{2.5}, \mathrm{PM}_{10}, \mathrm{CO}$, and $\mathrm{NO}_{2}$ presented "U-shaped" distributions. Table S3 also shows that there are highly positive correlations among $\mathrm{PM}_{2.5}, \mathrm{PM}_{10}$, $\mathrm{CO}$, and $\mathrm{NO}_{2}$. In particular, there is a strong correlation between $\mathrm{PM}_{2.5}$ and $\mathrm{PM}_{10}(r=0.969$, $p<0.01$ ), and $\mathrm{PM}_{2.5}$ is strongly correlated with $\mathrm{CO}$ and $\mathrm{NO}_{2}(r$ $=0.791$ and $r=0.647$, respectively; $p<0.01$ ). These results prove the close relations among $\mathrm{PM}_{2.5}, \mathrm{PM}_{10}$, $\mathrm{CO}$, and $\mathrm{NO}_{2}$ and show their strong homology and mutual transformation ability [5]. Monthly average concentrations of $\mathrm{PM}_{2.5}, \mathrm{PM}_{10}$, and CO during April-May and August-September increased to a small extent, which was mainly attributed to the combustion of straw. Nevertheless, the monthly concentration of $\mathrm{NO}_{2}$ presented no fluctuations.

The monthly variation of $\mathrm{O}_{3}$ concentration in Nanchong City presented an inverted "U-shaped" distribution in the last four years (Fig. 4(c)). Near-surface ozone $\left(\mathrm{O}_{3}\right)$ is the secondary pollution from precursors like VOCs and NOx through photochemical reaction under solar radiation [15]. The high concentration of near-surface $\mathrm{O}_{3}$ has strong oxidization and can greatly damage the physical health of humans, the ecosystem, and agricultural crops [54]. $\mathrm{O}_{3}$ generally has weak negative correlations with other pollutants [13]. This is because substances like NOx and CO can promote the production of a secondary pollutant such as $\mathrm{O}_{3}$ through photochemical reactions, and particles can generate an extinction effect, which is disadvantageous to the formation of $\mathrm{O}_{3}[13,55]$. This outcome also corresponds with the significantly negative correlations of $\mathrm{O}_{3}$ with $\mathrm{PM}_{2.5}, \mathrm{PM}_{10}, \mathrm{NO}_{2}$, and $\mathrm{CO}$ in Table S3. In addition, $\mathrm{O}_{3}$ shows a significantly positive correlation with temperature $(r$ $=0.541, p<0.01$ ) (Table S3). Under high temperature and strong solar radiation, NOx and VOCs easily develop photochemical reactions to produce $\mathrm{O}_{3}[5,56]$. Wind also has a positive effect on $\mathrm{O}_{3}[31,57]$; specifically, there is an obvious positive correlation 

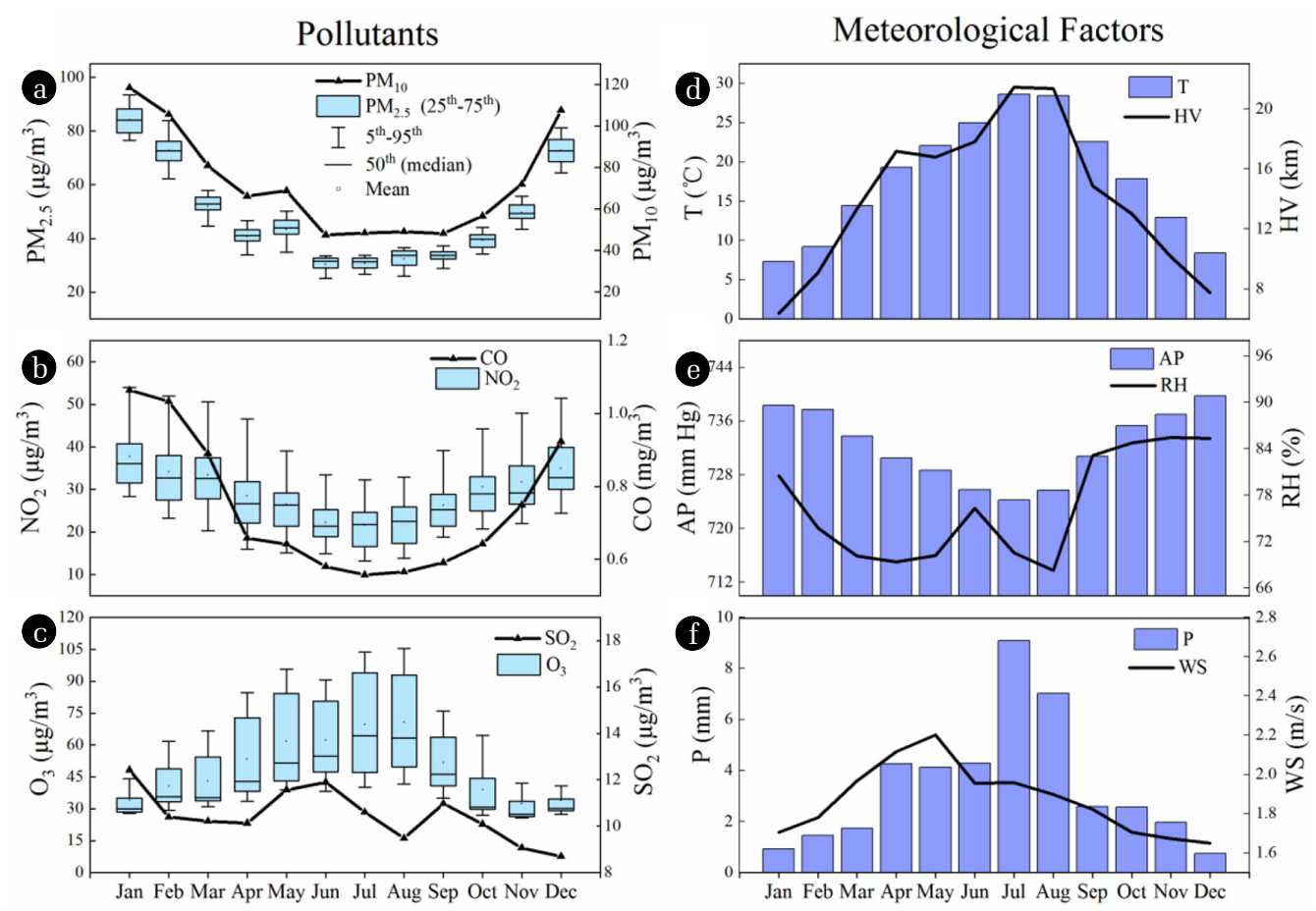

Month

Fig. 4. Monthly variations of pollutants $(\mathrm{a}-\mathrm{c})$ and meteorological factors $(\mathrm{e}-\mathrm{f})$. $\mathrm{T}$, temperature; HV, horizontal visibility; $\mathrm{AP}$, air pressure; RH, relative humidity; $\mathrm{P}$, precipitation; $\mathrm{WS}$, wind speed.

between wind speed and $\mathrm{O}_{3}(r=0.44, p<0.01)$ (Table S3). For this reason, $\mathrm{O}_{3}$ concentration in spring and summer increases greatly, and the peak concentration occurs in July and August. This finding conforms to the research results of Zhang et al. [16]. Solar radiation in autumn and winter decreases [32]. Furthermore, horizontal visibility and the production rate of $\mathrm{O}_{3}$ decline because of the increase in PM concentration, which significantly decreases $\mathrm{O}_{3}$ concentration in autumn and winter $[5,58]$. The "coal-to-gas" project was implemented in the main urban area of Nanchong City starting in 2000, and the total $\mathrm{SO}_{2}$ concentration in air was relatively low [35]. $\mathrm{SO}_{2}$ concentration in summer and autumn fluctuated slightly because of coal combustion in the urban areas, and the $\mathrm{SO}_{2}$ that entered the air from the coal combustion in the suburbs easily diffused to the urban areas because of the higher wind speed in spring and summer.

The highest pollutant concentration in the main urban area of Nanchong City generally occurred in winter, followed by spring and autumn, and the lowest was in summer. This finding could be interpreted as follows: the main urban area of Nanchong City is at the bottom of a basin and has a low-lying terrain as well as uneven distributions of meteorological factors among four seasons. According to Fig. 4f, there are few precipitations and low wind speed in winter but high quiet wind frequency. There are also weak illuminations, short illumination hours, and a strong and thick thermal inversion layer in winter [51], making pollutants in air difficult to diffuse [58]. Along with the effect of other factors (e.g., burning of coal and wood during the heating period), $\mathrm{PM}_{2.5}$, $\mathrm{PM}_{10}, \mathrm{SO}_{2}, \mathrm{CO}$, and $\mathrm{NO}_{2}$ in the study area were generally high in winter. On the contrary, summer is conducive to the diffusion and settlement of pollutants [51] due to the high temperature, high wind speed, strong atmospheric convective activity, shortening duration of thermal inversion layer, strengthened atmospheric turbulent mixing and vertical convection [52], low air pressure, and abundant precipitations. Table S3 shows that AQI has significantly negative correlations with temperature, precipitation, wind speed, relative humidity, and horizontal visibility $(r=-0.429,-0.414$, $-0.352,-0.132$, and -0549 , respectively; $p<0.01)$ and a positive correlation with air pressure $(r=0.417, p<0.01)$. To sum up, high temperature, low air pressure, high wind speed, and high relative humidity are beneficial to the dilution and diffusion of pollutants, and air quality is the collaborative consequence of various meteorological factors and pollution emissions by human activities. In the study area, temperature, air pressure, precipitation, and wind speed greatly influence air quality; in comparison, the effect of humidity on air quality is relatively small.

\subsection{Diurnal Variation Characteristics}

In view of the shapes of profiles, diurnal variations of $\mathrm{PM}_{2.5}, \mathrm{PM}_{10}$, $\mathrm{NO}_{2}$, and CO show evident bimodal distribution (Fig. 5(a)-(c), (e)). The two peaks occur after rush hours in the morning and evening. The first peak occurs after the rush hour in the morning when the mixing layer has not been developed completely. This period experiences poor turbulent diffusion in daytime [59] and large traffic flows, which increase $\mathrm{PM}, \mathrm{NO}_{2}$, and $\mathrm{CO}$ significantly. As time goes on, solar radiation and atmospheric turbulence activity 

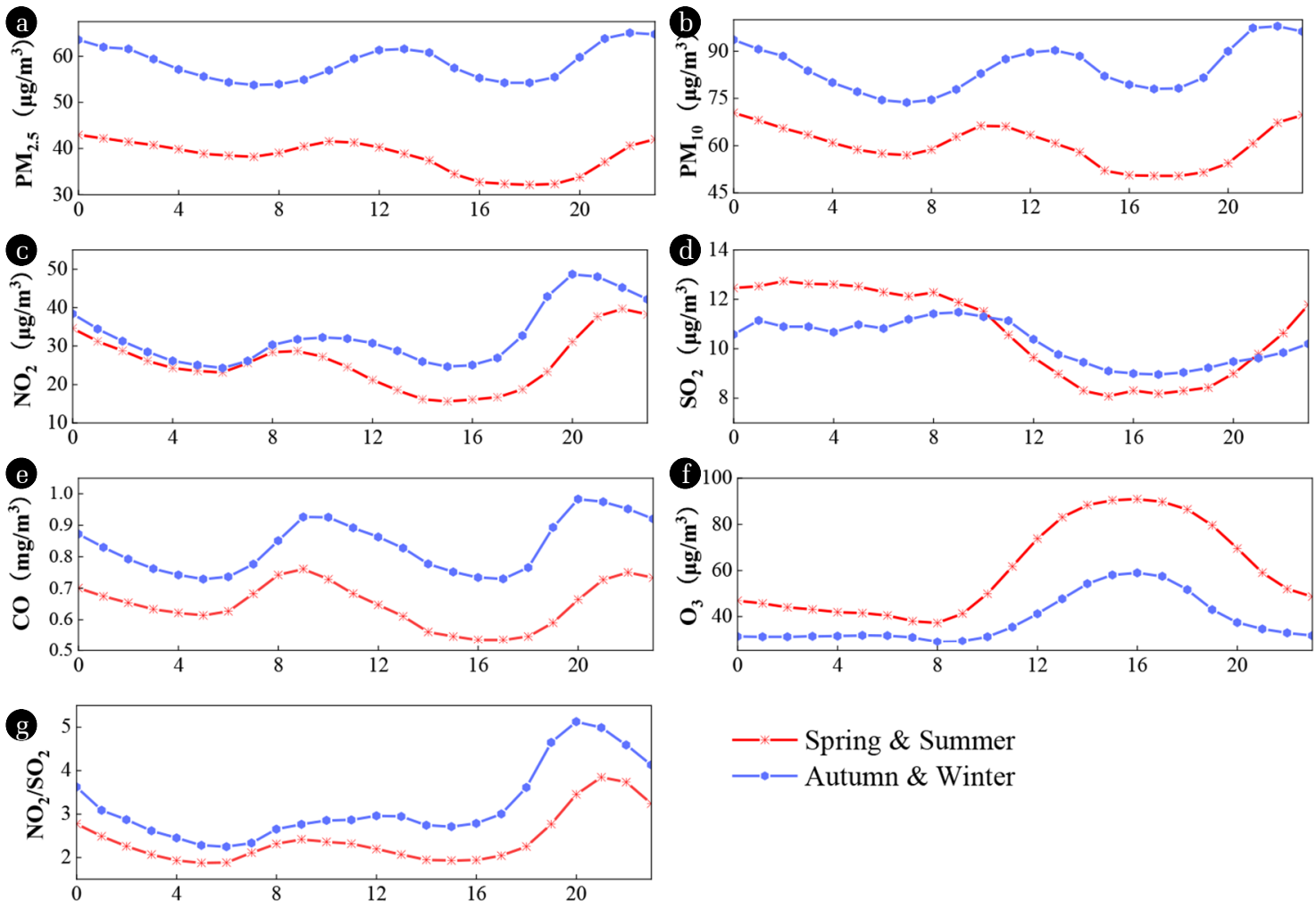

Time (h)

Fig. 5. Diurnal distribution characteristics of six elements of ambient air quality and $\mathrm{NO}_{2} / \mathrm{SO}_{2}$ in spring and summer as well as autumn and winter in the study area.

are strengthened in the afternoon, when the diffusion capacity of pollutants reaches the maximum level [24, 53]. As a result, the concentrations of $\mathrm{PM}_{2.5}, \mathrm{PM}_{10}, \mathrm{NO}_{2}$, and $\mathrm{CO}$ decrease. Subsequently, the height of the boundary layer decreases and a stable boundary layer is formed gradually at nightfall, weakening the atmospheric diffusion conditions [60]. Moreover, influenced by rush hours in the evening, the concentrations of $\mathrm{PM}_{2.5}, \mathrm{PM}_{10}$, $\mathrm{NO}_{2}$, and $\mathrm{CO}$ have their second peaks before 24:00. The second peak concentrations are significantly higher than the first peak concentrations. Meanwhile, $\mathrm{SO}_{2}$ concentration climbs up substantially. Different from $\mathrm{PM}_{2.5}, \mathrm{PM}_{10}, \mathrm{NO}_{2}$, and $\mathrm{CO}$, the diurnal variation of $\mathrm{SO}_{2}$ concentration presents a single-peak distribution (Fig. 5(d)). However, the diurnal variation distribution of $\mathrm{SO}_{2}$ is different from the bimodal distribution in some studies [25, 57], due to the fact that Nanchong City is a large agricultural city with underdeveloped industries, and the phenomenon of morning and evening peak caused by human activities is not obvious. $\mathrm{SO}_{2}$ concentration in the evening is substantially higher than that in the daytime because of the existence of $\mathrm{SO}_{2}$ in the evening and the better conditions for pollutant diffusion in the daytime than in the evening [60]. As a result, the lowest $\mathrm{SO}_{2}$ concentration is observed at 16:00. Diurnal variation characteristics of $\mathrm{NO}_{2} / \mathrm{SO}_{2}$ were analyzed (Fig. $5(\mathrm{~g})) . \mathrm{NO}_{2} / \mathrm{SO}_{2}$ presents an evident peak during the morning peak of $\mathrm{NO}_{2}$. This further proves that the environmental effect of mobile source emissions is stronger than that of fixed source emissions during rush hours in the morning. Concentrations of $\mathrm{PM}_{2.5}, \mathrm{PM}_{10}$, $\mathrm{NO}_{2}$, and $\mathrm{CO}$ are mainly influenced by vehicle exhausts. Therefore, these concentrations rise in the period with great vehicle activities and then decrease in rest periods. $\mathrm{SO}_{2}$ concentration is mainly influenced by atmospheric diffusion conditions. Generally, these conditions are relatively poor from evening to the next morning but good from late afternoon to early evening, resulting in a single-peak distribution in the diurnal variation curve of $\mathrm{SO}_{2}$.

Diurnal variation of $\mathrm{O}_{3}$ presents a single-peak distribution, which is opposite the diurnal variation of $\mathrm{SO}_{2}$ (Fig. 5(f)). Precursors produced by human activities in daytime, including VOCs and $\mathrm{NO}_{\mathrm{x}}$, generate $\mathrm{O}_{3}$ through photochemical reactions. Solar radiation is the strongest in the afternoon [16], and $\mathrm{O}_{3}$ concentration reaches its peak at about 16:00. However, $\mathrm{O}_{3}$ concentration in the evening declines significantly because of the absence of solar radiation and the titration effect of $\mathrm{NO}$ to $\mathrm{O}_{3}[61,62] . \mathrm{NO}_{2}$ can not only further promote the formation of particulates by producing nitrates [5] but also produce $\mathrm{O}_{3}$ through photochemical reactions [15]. Hence, the variations of $\mathrm{PM}_{2.5}$ and $\mathrm{PM}_{10}$ lag behind the variation of $\mathrm{NO}_{2}$ by about 1 hour, and the variation of $\mathrm{O}_{3}$ lags behind by about 2 hours. Abdul-Wahab et al. [63] found that solar levels contribute considerably to elevated daytime $\mathrm{O}_{3}$ concentrations with $\mathrm{NO}$, whereas $\mathrm{NO}_{2}$ is the major stimulus at night. In terms of diurnal variation of $\mathrm{PM}, \mathrm{NO}_{2}, \mathrm{SO}_{2}, \mathrm{CO}$, and $\mathrm{O}_{3}$, there is a clear variation in the level of pollutant concentration, which obviously follows 
the diurnal variation of atmospheric temperature and main anthropogenic and traffic activities.

According to seasonal differences in diurnal distributions of the six elements, concentrations of $\mathrm{PM}_{2.5}, \mathrm{PM}_{10}, \mathrm{NO}_{2}$, and $\mathrm{CO}$ in summer are significantly lower than those in winter. This outcome is consistent with existing research results [29] and is mainly determined by seasonal differences of atmospheric diffusion conditions [64]. (Fig. 4(d)-(f)) showed that the meteorological factors varied with the seasonal changes in Nanchong City. The synoptic model of pollution is generally related with relatively high surface pressure, low temperature, high relative humidity, and low wind speed [51]. Meteorological conditions in Sichuan Basin in winter are conducive for the formation of disadvantageous atmospheric diffusion conditions [65]. The high temperature in summer can facilitate atmospheric turbulence, thus increasing the diffusion of pollutants. Moreover, wet removal of pollutants increases with the increase in precipitation, which can lower pollutant concentrations [8,32]. The variation of $\mathrm{O}_{3}$ is the opposite. The production rate of $\mathrm{O}_{3}$ is mainly determined by solar radiation intensity [5]. $\mathrm{O}_{3}$ concentration increases in spring and summer due to the strengthened solar radiation but decreases in winter because of the weakening solar radiation [51]. Since human activity is affected by daytime and nighttime, variations of the six elements during the first peak in winter lag behind those in spring and summer, but the variations during the second peak are earlier (for 1-2 h).

A day and night comparison was conducted between the concentration of six elements in spring and summer and in autumn and winter. During the day, especially in the afternoon, the difference between spring and summer concentration and autumn and winter concentration increases, whereas the difference in nighttime concentration value decreases. This outcome is attributed to the great seasonal differences in terms of atmospheric diffusion conditions during daytime (08:00-20:00). Pollutant concentrations in spring and summer when there are good atmospheric diffusion conditions decrease greatly, thus increasing the differences compared to those in autumn and winter. Owing to the sharp reduction of emission sources, the concentrations of various pollutants at night are closer to the environmental background values, and the nocturnal diffusivity of different seasons is smaller than that of the daytime; hence, the nocturnal difference decreases. However, the concentration of $\mathrm{O}_{3}$ is mainly determined by the intensity of solar radiation [32], which is high during the day and low at night. In addition, there is high relative humidity in Sichuan Province in autumn and winter [60] (Fig. 4(e)), causing $\mathrm{SO}_{2}$ and $\mathrm{NO}_{2}$ to generate heterogeneous reactions easily and thus be consumed. Hence, the seasonal difference of $\mathrm{NO}_{2}$ decreases significantly at night compared to that during daytime, and $\mathrm{SO}_{2}$ concentration in autumn and winter is even lower than that in spring and summer.

\subsection{Interaction between $\mathrm{O}_{3}$ and $\mathrm{PM}_{2.5}$}

Currently, the composite air pollution is becoming more prominent in China [66, 67]. $\mathrm{PM}_{2.5}$ and $\mathrm{O}_{3}$ have become two major pollutants in composite air pollution [68]. Some studies have pointed out that concentrations of $\mathrm{PM}_{2.5}$ and $\mathrm{O}_{3}$ are related to the death rate and many health issues [69, 70]. Hence, the relations and interaction between $\mathrm{PM}_{2.5}$ and $\mathrm{O}_{3}$ have attracted the attention of scholars [71-73]. The monthly distribution patterns of daily variations of $\mathrm{PM}_{2.5}$ and $\mathrm{O}_{3}$ in Nanchong City are shown in Fig. 6. From April to August, the maxima of $\mathrm{O}_{3}$ concentration are achieved from late afternoon to early evening while the corresponding $\mathrm{PM}_{2.5}$ is the minimum. $\mathrm{PM}_{2.5}$ has an obviously negative correlation with $\mathrm{O}_{3}(r=-0.381$, $p<0.01$ ) (Table S3). In other periods, the correlation is not obvious. Hence, the relationship between $\mathrm{PM}_{2.5}$ and $\mathrm{O}_{3}$ is further studied according to their interaction.

\subsubsection{Effects of $\mathrm{PM}_{2.5}$ on $\mathrm{O}_{3}$}

The effects of $\mathrm{PM}_{2.5}$ on $\mathrm{O}_{3}$ are mainly determined by the production rate of $\mathrm{O}_{3}$ under three $\mathrm{PM}_{2.5}$ concentrations. As shown in Fig. 7(a) and $7(b), \mathrm{O}_{3}$ concentration decreases significantly with the increase in $\mathrm{PM}_{2.5}$ concentration. Furthermore, $\mathrm{O}_{3}$ concentration presents consistent variation trends under three $\mathrm{PM}_{2.5}$ concentrations. Specifically, the absolute variation rate of $\mathrm{O}_{3}$ is low during 24:00-08:00, which centers on consumption. However, $\mathrm{O}_{3}$ concen-

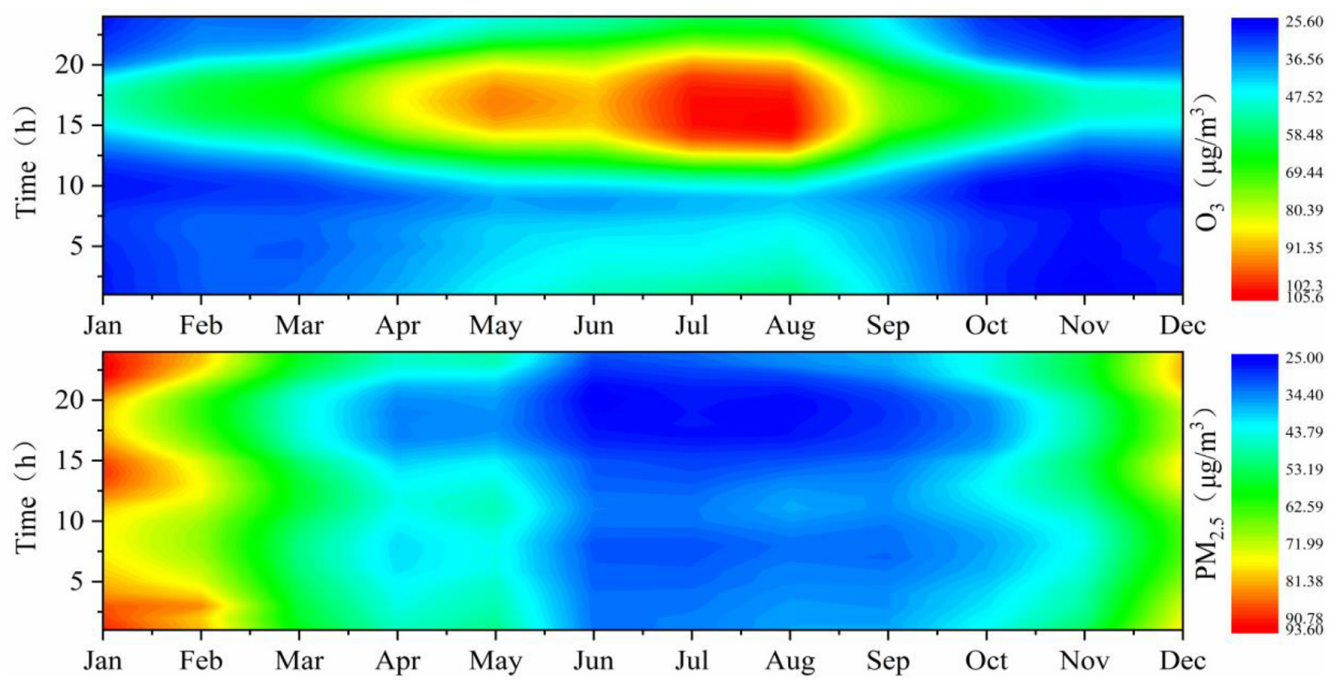

Fig. 6. Monthly distribution of daily variations of $\mathrm{O}_{3}$ and $\mathrm{PM}_{2.5}$ 

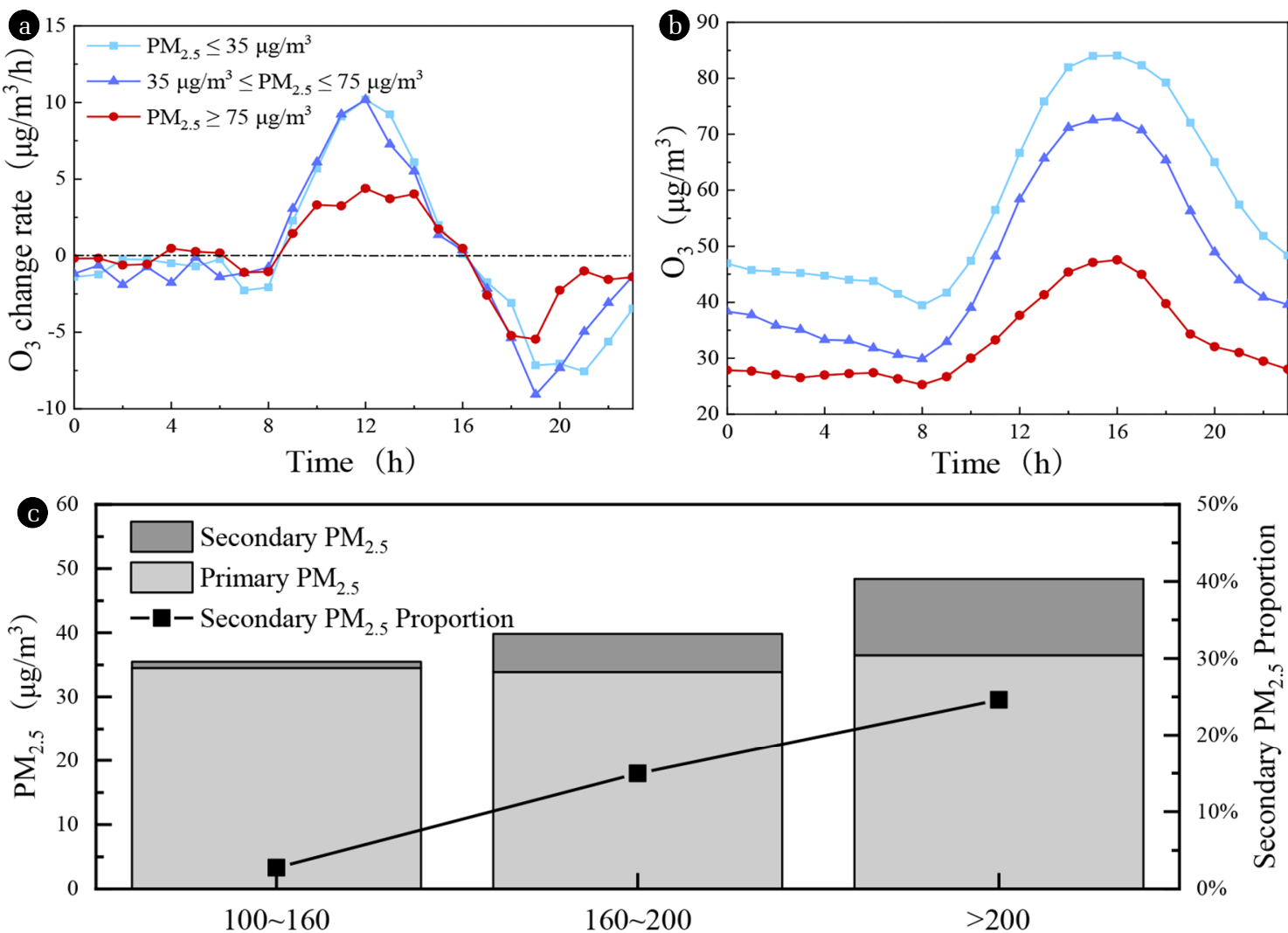

Different $\mathrm{O}_{3}$ concentration levels $\left(\mu \mathrm{g} / \mathrm{m}^{3}\right)$

Fig. 7. (a) Hourly variation rate of $\mathrm{O}_{3}$ under different $\mathrm{PM}_{2.5}$ concentrations, (b) Diurnal variation of $\mathrm{O}_{3}$ under different $\mathrm{PM}_{2.5}$ concentrations,

(c) Percentages of primary and secondary $\mathrm{PM}_{2.5}$ under different $\mathrm{O}_{3}$ concentrations in Nanchong City.

tration subsequently increases greatly. The variation rate of $\mathrm{O}_{3}$ reaches the maxima at 12:00 (Fig. 7(a)). The growth rate of $\mathrm{O}_{3}$ concentration when the $\mathrm{PM}_{2.5}$ concentration meets the standard $\left(\mathrm{PM}_{2.5}<75 \mu \mathrm{g} / \mathrm{m}^{3}\right)$ is the highest. Before 08:00, the temperature is low, the solar radiation is weak, the $\mathrm{O}_{3}$ generation rate is low and the formation process is not significant. Over time, the temperature rises after sunrise and solar radiation increases, leading to a significant increase in ozone formation and its concentration reaches the peak at 16:00 (Fig. 7(b)). Subsequently, $\mathrm{O}_{3}$ concentration begins to decrease continuously and reaches the minimum at nightfall. When there is $\mathrm{PM}_{2.5}$ pollution $\left(\mathrm{PM}_{2.5}>75 \mu \mathrm{g} / \mathrm{m}^{3}\right)$, the production rate of $\mathrm{O}_{3}$ is clearly relatively low. These results demonstrate that $\mathrm{PM}_{2.5}$ can inhibit the generation of $\mathrm{O}_{3}$ in Nanchong City, and such inhibition effect is strengthened greatly when there is $\mathrm{PM}_{2.5}$ pollution $\left(\mathrm{PM}_{2.5}>75 \mu \mathrm{g} / \mathrm{m}^{3}\right)$ during daytime.

The main effects of $\mathrm{PM}_{2.5}$ on $\mathrm{O}_{3}$ are the direct radiation effects and the heterogeneous effects [74]. The increase of aerosol concentration will increase the consumption of $\mathrm{O}_{3}$ precursors (NOx) by heterogeneous reactions, which will lead to the decrease of $\mathrm{O}_{3}$ concentration [75]. Furthermore, the increase of aerosol concentration can cause significant loss of $\mathrm{O}_{3}$ concentration, which may be due to the direct radiative forcing effect of aerosol [76]. On the one hand, $\mathrm{PM}$ is rich in $\mathrm{BC}$, sulfate, nitrate, and other extinction components, all of which can greatly weaken horizontal visibility [13]. On the other hand, PM can change the optical thickness of clouds by influencing the microphysical process, thus further affecting solar shortwave radiation on the surface [77]. Accordingly, high-concentration PM can inhibit the production of $\mathrm{O}_{3}$ by weakening the near-surface photochemical activity.

\subsubsection{Effects of $\mathrm{O}_{3}$ on $\mathrm{PM}_{2.5}$}

As shown in Table S3, there has evident correlation between $\mathrm{PM}_{2.5}$ and CO $(r=0.791, p<0.01)$. Furthermore, CO is a primary pollutant with stable chemical properties, the atmospheric oxidation is relatively low when the $\mathrm{O}_{3}$ concentration is low $\left(\mathrm{O}_{3}<100 \mu \mathrm{g} / \mathrm{m}^{3}\right.$ in this study) and most $\mathrm{PM}_{2.5}$ are primary pollutants. According to the Formula (2) mentioned above, the primary $\mathrm{PM}_{2.5}$ concentration under different $\mathrm{O}_{3}$ concentrations can generally be estimated according to $(C O)_{T, i} \times\left(\mathrm{PM}_{2.5} / \mathrm{CO}\right)_{L}$, thus enabling the estimation of the secondary $\mathrm{PM}_{2.5}$ concentration. The effects of $\mathrm{O}_{3}$ on $\mathrm{PM}_{2.5}$ was studied by assessing the proportion of secondary particulate matter at different levels of $\mathrm{O}_{3}$ concentration. The calculated results are shown in Fig. 7 (c). The primary $\mathrm{PM}_{2.5}$ concentrations are 34.52, $33.87 \mu \mathrm{g} / \mathrm{m}^{3}$, and $36.48 \mu \mathrm{g} / \mathrm{m}^{3}$ when the $\mathrm{O}_{3}$ concentration is $100-160$, $160-200$, and $>200 \mu \mathrm{g} / \mathrm{m}^{3}$, respectively. Such small differences in primary $\mathrm{PM}_{2.5}$ concentrations indicate that local emission sources 
are relatively stable. Under this circumstance, the secondary $\mathrm{PM}_{2.5}$ concentrations are $0.98,5.96$, and $11.90 \mu \mathrm{g} / \mathrm{m}^{3}$, which account for $2.75 \%, 14.96 \%$, and $24.60 \%$, respectively. The concentration of secondary $\mathrm{PM}_{2.5}$ increases significantly with the increase in $\mathrm{O}_{3}$ concentration. In China, secondary particulates are typically generated by oxidative reaction [78]. With its strong oxidation property, $\mathrm{O}_{3}$ is the major oxidizing agent in the atmosphere, and it can cause indirect effects on the formation of secondary particulates [57]. The concentration change of secondary $\mathrm{PM}_{2.5}$ is obvious, indicating that atmospheric oxidation is strengthened with the increase in $\mathrm{O}_{3}$ concentration, which in turn increases the generation of secondary $\mathrm{PM}_{2.5}$. To sum up, $\mathrm{O}_{3}$ can promote the formation of $\mathrm{PM}_{2.5}$.

Generally speaking, the study concerns the interaction between $\mathrm{PM}_{2.5}$ and $\mathrm{O}_{3}$ plays an important role in air pollution control [74, 75, 79, 80]. Specifically, particulate matter has a significant attenuation effect on downward shortwave radiation (DSR), and the relative humidity could enhance the attenuation effect, resulting in a decrease in $\mathrm{O}_{3}$ concentration [75]. Diffusion conditions are unfavorable in winter, the concentrations of gaseous pollutants and aerosols increased obviously [75], leading to the significant attenuation effect on DSR. In winter, the inhibition effect of $\mathrm{PM}_{2.5}$ on $\mathrm{O}_{3}$ dominates the change of urban air composite pollution in Nanchong. However, during summer, precipitation is abundant, the wet precipitation of particulate matter is remarkable, and the strong radiation and high temperature in summer will enhance the photochemical reaction, which is beneficial to the formation of $\mathrm{O}_{3}$. As a result, the formation of secondary particles is easy to be promoted. Therefore, different measures should be taken in the treatment of atmospheric pollution according to seasonal variations in these two main pollutants. And $\mathrm{PM}_{2.5}$ emission should be controlled strictly in winter, while in summer, the sources of $\mathrm{O}_{3}$ should be controlled vigorously [79].

\section{Conclusions}

Overall, the air quality of the main urban area of Nanchong City reached the standard during 2015-2018 and improved continuously. Nowadays, the continuous over-standard of annual average $\mathrm{PM}_{2.5}$ and increasing $\mathrm{O}_{3}$ concentration are the two major challenges to air quality.

The monthly average mass concentrations of $\mathrm{PM}_{2.5}, \mathrm{PM}_{10}, \mathrm{NO}_{2}$, and $\mathrm{CO}$ are high in winter but low in summer, showing a "U-shaped" distribution pattern. Moreover, the correlations among these pollutants are significant and positive, whereas the distribution of $\mathrm{O}_{3}$ is the opposite and is negatively correlated with other pollutants. Temperature, wind speed, air pressure, and precipitation influence air quality greatly.

Diurnal variations of $\mathrm{SO}_{2}$ and $\mathrm{O}_{3}$ present opposite single-peak distribution patterns. They are mainly influenced by atmospheric diffusion conditions and solar radiation, respectively. Diurnal variations of $\mathrm{PM}, \mathrm{NO}_{2}$, and $\mathrm{CO}$ present bimodal distribution due to the morning and evening rush hours. According to our analysis, mobile sources make greater contributions to air pollution compared to fixed sources.

There is an obvious interaction between $\mathrm{PM}_{2.5}$ and $\mathrm{O}_{3}$. The in- crease in $\mathrm{PM}_{2.5}$ concentration, especially when it exceeds the standard $\left(>75 \mu \mathrm{g} / \mathrm{m}^{3}\right)$, will decrease the photochemical activity in the atmosphere and the rate of $\mathrm{O}_{3}$ production. However, $\mathrm{O}_{3}$ can promote the formation of secondary $\mathrm{PM}_{2.5}$ by increasing atmospheric oxidation. Overall, $\mathrm{PM}_{2.5}$ emission should be controlled strictly in winter, while in summer, the sources of $\mathrm{O}_{3}$ should be controlled vigorously. In addition, the study area should increase administration efforts to control anthropogenic source emissions like mobile sources.

\section{Acknowledgments}

The authors sincerely thank Sichuan Nanchong Ecological Environment Monitoring Center for the permission to use their data. This study was supported by the Teaching reform project-SPSS based on statistical software (No. 403/403619). The opinions in this study do not reflect the views or policies of Sichuan Nanchong Ecological Environment Monitoring Center.

\section{Author Contributions}

X.L. (M.D) wrote and revised the manuscript. Q.Z. (Postgraduate Student) wrote and revised the manuscript. Y.F.Q. (M.D) and J.H. (M.D) made significant contributions to data acquisition, analysis, and interpretation. D.Y.L. (M.D), P.Z. (Postgraduate Student), and X.Y. (Postgraduate Student) helped organize the manuscript data. Q.M.Q. (Professor) and Y.X.L. (Professor) made key changes to important academic content and were responsible for the final revision.

\section{References}

1. Fan H, Zhao CF, Yang YK. A comprehensive analysis of the spatio-temporal variation of urban air pollution in China during 2014-2018. Atmos. Environ. 2020;220:117066.

2. He H, Wang XM, Wang YS, et al. Formation Mechanism and Control Strategies of Haze in China. Bull. Chin. Acad. Sci. 2013;3(3):344-352. (In Chinese).

3. An ZS. Relying on scientific and technological progress to speed up $\mathrm{PM}_{2.5}$ pollution control in China Progress with Air Quality Improvement. Sci. Technol. Rev. 2015;33(6):1-1. (In Chinese).

4. Cao JJ. Major causes and control strategies of the $\mathrm{PM}_{2.5}$ pollution in China. Sci. Technol. Rev. 2016;34(20):74-80. (In Chinese).

5. Xu MC, Zhang LJ, Zheng N, et al. Analysis on the change trend and pollution characteristics of urban air quality after revision of ambient air quality standards: take Jinan City as an example. Sci. Technol. Eng. 2020;20(13):5422-5428. (In Chinese).

6. Chang MY, Xiang WG. Characteristics of Air Pollution in Western Sichuan and Analysis of Meteorological Factors. J. Chendu Univ. Inf. Eng. 2019;34(01):92-99. (In Chinese).

7. Zang XH, Lu YT, Yao H, et al. The temporal and spatial distribution characteristics of main air pollutants in China. Ecol. Environ. Sci. 2015;24(8):1322-1329. 
8. Yang JH, Ji ZM, Kang SH, Zhang QG, Chen XT, Lee SY. Spatiotemporal variations of air pollutants in western China and their relationship to meteorological factors and emission sources. Environ. Pollut. 2019;254:112952.

9. Tang XY, Zhang YH. Atmospheric environmental chemistry. Beijing: Higher Education Press; 2006. (In Chinese).

10. Zhou Q, Zhang L, Yang L, et al. Long-term variability of inorganic ions in TSP at a remote background site in Japan (Wajima) from 2005 to 2015. Chemosphere 2021;264:128427.

11. Kim IS, Lee JY, Wee D, Kim YP. Estimation of the contribution of biomass fuel burning activities in North Korea to the air quality in Seoul, South Korea: Application of the 3D-PSCF method. Atmos. Res. 2019;104628.

12. Yang KH, Xia ZY, He P, et al. Correlation of fuel quality and emissions of motor vehicle with atmospheric pollution in Beijing. J. Univ. Chin. Acad. Sci. 2017;34(3):304-317.

13. Ma T, Duan FK, He KB, et al. Air pollution characteristics and their relationship with emissions and meteorology in the Yangtze River Delta region during 2014-2016. J. Environ. Sci. 2019;83:8-20.

14. Zhao P, Tuygun GT, Li B, et al. The effect of environmental regulations on air quality: A long-term trend analysis of $\mathrm{SO}_{2}$ and $\mathrm{NO}_{2}$ in the largest urban agglomeration in southwest China. Atmos. Pollut. Res. 2019;10(6):2030-2039.

15. Fishman J, Grutzen PJ. The origin of ozone in troposphere. Nature 1978;274:855-858.

16. Zhang XJ, Li L, Wang HL, et al. Preliminary study on the long-term trends of ozone in urban Shanghai from 2010 to 2016. Acta Sci. Circumst. 2019;39(1):86-94.

17. Li XL, Yang X. Analysis of Environmental Air Quality Characteristics and the Correlation with Meteorological Factors in the Urban Area of Zigong City from 2016 to 2018. SiChuan. Environ. 2020;39(03):59-66.

18. Vuong QT, Thang PQ, Nguyen TNT, et al. Seasonal variation and gas/particle partitioning of atmospheric halogenated polycyclic aromatic hydrocarbons and the effects of meteorological conditions in Ulsan, South Korea. Environ. Pollut. 2020;263: 114592.

19. Thang PQ, Kim SJ, Lee SJ, et al. Monitoring of polycyclic aromatic hydrocarbons using passive air samplers in Seoul, South Korea: Spatial distribution, seasonal variation, and source identification. Atmos. Environ. 2020;229:117460.

20. Tian Y, Yao XB, Chen LB. Analysis of spatial and seasonal distributions of air pollutants by incorporating urban morphological characteristics. Comput. Environ. Urban. Syst. 2019;75:35-48.

21. Yang JH, Ji ZM, Kang SH, Zhang QG, Chen XT, Lee SY. Spatiotemporal variations of air pollutants in western China and their relationship to meteorological factors and emission sources. Environ. Pollut. 2019;254:112952

22. Wu C, Hu W, Zhou M, Li S, Jia Y. Data-driven regionalization for analyzing the spatiotemporal characteristics of air quality in China. Atmos. Environ. 2019;203:172-182.

23. Wang K, Yin H, Chen Y. The effect of environmental regulation on air quality: A study of new ambient air quality standards in China. J. Clean. Prod. 2019;215:268-279.

24. Zhan CC, Xie M, Fang DX, et al. Synoptic weather patterns and their impacts on regional particle pollution in the city cluster of the Sichuan Basin, China. Atmos. Environ. 2019;208:34-47.

25. Li B, Shi XF, Liu YP, et al. Long-term characteristics of criteria air pollutants in megacities of Harbin-Changchun megalopolis, Northeast China: Spatiotemporal variations, source analysis, and meteorological effects. Environ. Pollut. 2020;267:115441.

26. Chen L, Zhu J, Liao H, Yang Y, Yue X. Meteorological influences on $\mathrm{PM}_{2.5}$ and $\mathrm{O}_{3}$ trends and associated health burden since China's clean air actions. Sci. Total Environ. 2020;744:140837.

27. She YY, Li ZQ, Wang FL, et al. Variation characteristics and potential source analysis of atmospheric pollutants in west of the Qinling-Daba Mountains from 2015 to 2018. Acta Sci. Circumst. 2020;40(6):1987-1997. (In Chinese).

28. Li XF, Zhang JM, Wang SJ, et al. Variation Characteristics and Influencing Factors of Air Pollution Index in China. Chin. J. Environ. Sci. 2012;33(6):1936-1943. (In Chinese).

29. Yang HA, Dan SM. Analysis J Winter Wind Speed, Precipitation and Air Pollution Concentration in Sichuan Basin. Sichuan. Meteorol. 1995(03):28-30. (In Chinese).

30. Liang L, Engling G, Zhang X, et al. Chemical characteristics of $\mathrm{PM}_{2.5}$ during summer at a background site of the Yangtze River Delta in China. Atmos. Res. 2017;198:163-172.

31. Wang Y, Li Y, Qiao Z, Lu Y. Inter-city air pollutant transport in The Beijing-Tianjin-Hebei urban agglomeration: Comparison between the winters of 2012 and 2016. J. Environ. Manage. 2019;250:109520.

32. Lu X, Yao T, Fung JCH, Lin C. Estimation of health and economic costs of air pollution over the Pearl River Delta region in China. Sci. Total Environ. 2016;566-567:134-143.

33. Xiao CC, Chang M, Guo PK, Gu M, Li Y. Analysis of air quality characteristics of Beijing-Tianjin-Hebei and its surrounding air pollution transport channel cities in China. J. Environ. Sci (China). 2020;87:213-227.

34. Lei X, Du W, Li DY, Sheng HF, Qian YF. Analysis on the Characteristics and Sources of Volatile Organic Compounds in Autumn in the Urban of Nanchong City. Sichuan. Environ. 2020;39(02):55-64. (In Chinese).

35. Li TS, Fang YX, Zhang HZ, Guo B, Zhang J. Fuel Switching Project from Coalto Natura lGasin South west China: Case Study of Nanchong City, Sichuan. J. Chin. West. Norm. Univ (Nat. Sci). 2005(01):85-88. (In Chinese).

36. Luo HX, Song T, Zhang ZQ, et al. Study on the characteristics of Acid Rain in Nanchong City from 2009 to 2017. Environ. Monit. Chin. 2020;36(01):82-87. (In Chinese).

37. Zang XH, Lu YT, Yao H, et al. The temporal and spatial distribution characteristics of main air pollutants in China. Ecolo \& Enviro. Sci. 2015;24(8):1322-1329.

38. Shu L, Luo B, Hu J, et al. Emission inventory and characteristics of atmosphere $\mathrm{PM}_{2.5}$ and $\mathrm{PM}_{10}$ in Nanchong. Environ. Monit. Chin. 2018;34(03):84-92. (In Chinese).

39. Ministry of Environmental Protection. GB 3095-2012 Ambient air quality standards. Beijing: China Environmental Science Press, 2012.

40. Chang SC, Lee CT. Secondary aerosol formation through photochemical reactions estimated by using air quality monitoring data in Taipei City from 1994 to 2003. Atmos. Environ. 
2007;41(19):4002-4017.

41. Nguyen GTH, Shimadera H, Uranishi K, Matsuo T, Kondo A, Thepanondh S. Numerical assessment of $\mathrm{PM}_{2.5}$ and $\mathrm{O}_{3}$ air quality in continental Southeast Asia: Baseline simulation and aerosol direct effects investigation. Atmos. Environ. 2019;219:117054.

42. Racherla PN, Adams PJ. Sensitivity of global tropospheric ozone and fine particulate matter concentrations to climate change. J. Geophys Res. Atmos. 2006;111(24):1-11.

43. Zhong QQ, Wang KP, Chen JJ, Zhang YW, Fu SJ. Evaluation and variation feature analysis of the air quality over Nanchong area in 2014. Plateau. Mountain. Meteor. Res. 2015;35(03):78-83. (In Chinese).

44. Shi Y, Wang N, Yang LY. Analysis of the Influences of the New Ambient Air Quality Standard on Completion of the $12^{\text {th }}$-five-year Plan Targets. Environ. Protect. Sci. 2017;43(01):26-29. (In Chinese).

45. Wang KB, Qian YF, Xiong L, et al. The origin brief analysis of ambient air quality change and air pollution in Nanchong urban area during the Twelfth Five-year. SiChuan. Environ. 2016;(6):89-94. (In Chinese).

46. Li WP, Li K, Wang J, et al. The main related factor and seasonal variation of fine particulate matter concentration in the typical low mountain terrain urban - a case in Nanchong in northeastern Sichuan. J. Earth. Environ. 2017;(05):65-76. (In Chinese).

47. Long LF, Wang XM, Feng BZ, Zhang YL, Yang HF. Exposure levels of $\mathrm{PM}_{2.5}$ and $\mathrm{CO}$ at bus stations in urban Guangzhou. Environ. Sci. Technol. 2010;33(09):140-145. (In Chinese).

48. Chen CY, Yin XB. Source, composition, formation and harm of $\mathrm{PM}_{2.5}$ in haze. Univ. Chem. 2014;29(05):1-6. (In Chinese).

49. Bai CL. Progress and prospect on atmospheric haze research in Chinese academy of sciences. Bull. Chin. Acad. Sci. 2014;(3):275-281. (In Chinese).

50. Zhao D, Chen H, Yu E, Luo T. $\mathrm{PM}_{2 .} / \mathrm{PM}_{10}$ Ratios in Eight Economic Regions and Their Relationship with Meteorology in China. Adv. Meteorol. 2019;2019:1-15.

51. Liu H. Characteristics of Air Pollutants in Taijiang District of Fuzhou City and Its Correlation with Meteorological Factors. Straits. Sci. 2019;000(012):3-5,19. (In Chinese).

52. Li J, lv AH, Li JG. The Analysis of Variation Characteristics of Air Pollution and Influential Factors during the Eleventh "Five-Year Plan" in Urumqi City. Environ. Monit. Chin. 2014;30(02):14-20. (In Chinese).

53. Zhang CH, Li FS, Zhao LM, Guo SJ. Correlations between air quality status and meteorological factors in Hohhot city. J. Arid Land. Resour. Environ. 2018;32(02):87-93. (In Chinese).

54. Wang HX, Kiang CS, Tang XY, et al. Surface ozone: A likely threat to crops in Yangtze delta of China. Atmos. Environ. 2005;39(21):3843-3850.

55. Pusede SE, Steiner AL, Cohen RC. Temperature and recent trends in the chemistry of continental surface ozone. Chem. Rev. 2015;115 (10):3898-3918.

56. Characteristics of Atmospheric Pollutant Concentration in Major Cities of Yunnan Province from 2015 to 2016 and Its Relationship with Meteorological Elements. Environ. Sci. Survey. 2018;37(06):40-45. (In Chinese).

57. Al-Harbi M, Abahussain A. Spatiotemporal variations and source apportionment of $\mathrm{NOx}, \mathrm{SO}_{2}$, and $\mathrm{O}_{3}$ emissions around heavily industrial locality. Environ. Eng. Res. 2020;25(2):147-162. 58. Fatemeh YF, Sasan F, Faramarz AM, et al. Temporal variations of ambient air pollutants and meteorological influences on their concentrations in Tehran during 2012-2017. Sci. Rep. 2020;10(1).

59. Sorbjan, Zbigniew. The atmospheric boundary layer. Atmospheric boundary layer flows: Oxford University Press; 2002. p. 225-250.

60. Sun YL, Zhao TL, Qiu YJ, et al. The vertical change in extinction effect of particles during a haze episode in Chengdu. China. Environ. Sci. 2018;38(05):31-38. (In Chinese).

61. Wang YH. Physical and chemical properties of atmospheric aerosols and their effects on extinction and ozone concentrations. Lanzhou: Lanzhou University; 2015. (In Chinese).

62. Barzeghar V, Sarbakhsh P, Hassanvand MS, et al. Long-term trend of ambient air $\mathrm{PM}_{10}, \mathrm{PM}_{2.5}$, and $\mathrm{O}_{3}$ and their health effects in Tabriz city, Iran, during 2006-2017. Sustain. Cities. Soc. 2020;54:101988

63. Abdul-Wahab S, Bakheit C, Al-Alawi S. Principal component and multiple regression analysis in modelling of ground-level ozone and factors affecting its concentrations. Environ. Modell. Softw. 2005;20:1263-1271.

64. Yang J, Ji Z, Kang S, Zhang Q, Chen X, Lee SY. Spatiotemporal variations of air pollutants in western China and their relationship to meteorological factors and emission sources. Environ. Pollut. 2019;254:112952

65. Liao T, Gui K, Jiang W, et al. Air stagnation and its impact on air quality during winter in Sichuan and Chongqing, southwestern China. Sci. Total Environ. 2018;635:576-585.

66. Wang Z, Li Y, Chen T, et al. Changes in atmospheric composition during the 2014 APEC conference in Beijing. J. Geophys Res. Atmos. 2015;120(24):12695-12707.

67. Zhao H, Zheng YF, Wei L, Guan Q, Wang ZS. Evolution and evaluation of air quality in Hangzhou and its surrounding area during the G20 summit. China. Environ. Sci. 2017;37(6): 2016-2024. (In Chinese).

68. He KB. Atmospheric particulate matter and regional complex pollution. Science: Beijing Press; 2011. (In Chinese).

69. Wang H, Zhu Y, Jang C, et al. Design and demonstration of a next-generation air quality attainment assessment system for $\mathrm{PM}_{2.5}$ and $\mathrm{O}_{3}$. J. Environ. Sci (China). 2015;29:178-188.

70. Lin H, Guo Y, Ruan Z, et al. Ambient $\mathrm{PM}_{2.5}$ and $\mathrm{O}_{3}$ and their combined effects on prevalence of presbyopia among the elderly: A cross-sectional study in six low- and middle-income countries. Sci. Total Environ. 2019; 655:168-173.

71. Lei R, Zhu F, Cheng $\mathrm{H}$, et al. Short-term effect of $\mathrm{PM}_{2.5} / \mathrm{O}_{3}$ on non-accidental and respiratory deaths in highly polluted area of China. Atmos. Pollut. Res. 2019;10(5):1412-1419.

72. Zhong M, Chen F, Saikawa E. Sensitivity of projected $\mathrm{PM}_{2.5^{-}}$ and $\mathrm{O}_{3}$-related health impacts to model inputs: A case study in mainland China. Environ. Int. 2019;123:256-264.

73. Siddika N, Rantala AK, Antikainen H, et al. Synergistic effects of prenatal exposure to fine particulate matter $\left(\mathrm{PM}_{2.5}\right)$ and ozone $\left(\mathrm{O}_{3}\right)$ on the risk of preterm birth: A population-based cohort study. Environ. Res. 2019;176:108549.

74. Zhang YJ, Zhao TL, Yin CZ. Seasonal variation of the relationship 
between surface $\mathrm{PM}_{2.5}$ and $\mathrm{O}_{3}$ concentrations in Xuzhou. Chin. Environ. Sci. 2019;39(06):2267-2272. (In Chinese).

75. Li JH, Liu HN, Wang XY, et al. Observation Analysis on Aerosol and Ozone Interaction in Suzhou. Adm. Technol. Environ. Monit. 2019;31(01):29-33. (In Chinese).

76. Feng T. Summertime ozone formation in Xi'an and surrounding areas, China. Atmos. Chem. Phys. 2016;7(16):4323-4342.

77. Huang JP, Wang WC. Using CERES and CALIPSO data to study the possible effects of aerosol in dust clouds on climate. Fifth Subtropical Meteorological Symposium. 2009. p. 88.
78. Huang RJ, Zhang YL, Bozzetti C, et al. High secondary aerosol contribution to particulate pollution during haze events in China. Nature 2014;514(7521):218-222.

79. Shang YY, Shu ZZ, Zheng XS, et al. Interaction mechanism between $\mathrm{PM}_{2.5}$ and $\mathrm{O}_{3}$ in winter and summer in Yunnan-Guizhou plateau: a case study of Guiyang. Ecolog. Environ. Sci. 2018;27(12): 2284-2289. (In Chinese).

80. Zhu J, Chen L, Liao H, et al. Correlations between $\mathrm{PM}_{2.5}$ and Ozone over China and Associated Underlying Reasons. Atmosphere 2019;10(7):352. 